\title{
PRÁTICAS SUSTENTÁVEIS NAS ETAPAS DE PRODUÇÃO DE UMA INDÚSTRIA METAL MECÂNICA DO SUL DE SANTA CATARINA
}

\section{SUSTAINABLE PRACTICES IN PRODUCTION OF AN INDUSTRIAL METAL MECHANICS LOCATED IN THE SOUTH OF SANTA CATARINA}

\author{
Catarini Spillere ${ }^{1}$ \\ Julio Cesar Zilli ${ }^{2}$ \\ Adriana Carvalho Pinto Vieira ${ }^{3}$ \\ Marcelo Gryczak ${ }^{4}$ \\ Izabel Regina de Souza ${ }^{5}$
}

\begin{abstract}
Resumo
A indústria metal mecânica é destaque no desenvolvimento do país, pois contempla em seus produtos, desde as indústrias automobilísticas, construção civil, implementos agrícolas, rodoviários, maquinários, entre tantos produtos. É uma indústria fornecedora de tantas outras indústrias que fortalecem a economia nacional. Porém, este segmento sempre foi visto como indústria poluidora, devido os dejetos derivados de seus processos produtivos. Diante disto, o estudo objetivou identificar as práticas sustentáveis na fundição, laminação e trefilação de uma indústria metal mecânica do Sul de Santa Catarina. Em relação à metodologia, caracteriza-se quanto aos fins como uma pesquisa descritiva, e quanto aos meios de investigação, como uma pesquisa bibliográfica e um estudo de caso. Os dados foram coletados por meio de uma visita in loco na indústria e também por meio de uma entrevista com engenheiros e diretor industrial, para compreender todos os processos em estudo. Com o apoio de profissionais capacitados, a indústria comtempla em suas atividades industriais práticas sustentáveis no processo de laminação, trefilação e fundição, envolvendo o tratamento e reaproveitamento de água, separação de água e óleo, reutilização de toalhas industriais, reutilização de sucatas como matéria prima e reciclagem de produtos com outras empresas especializadas.
\end{abstract}

Palavras-chave: Sustentabilidade. Indústria. Metal mecânico.

\begin{abstract}
The metal mechanical industry is prominent in the development of the country as it includes in its products, from automotive industries, construction, agricultural, road, machinery, among many products. It is a supplier industry in so many other industries that strengthen the national economy. However, this segment has always been seen as polluting industry because the waste derived from their production processes. Given this, the study aimed to identify sustainable practices in casting, rolling and drawing a

\footnotetext{
1 Graduada em Administração, Universidade do Extremo Sul Catarinense - UNESC, e-mail: kaka_pspillere@hotmail.com

${ }^{2}$ Mestre em Desenvolvimento Socioeconômico, Universidade do Extremo Sul Catarinense - UNESC, email: zilli42@hotmail.com

${ }^{3}$ Doutora em Desenvolvimento Econômico, Universidade do Extremo Sul Catarinense - UNESC, e-mail: dricpvieira@gmail.com

4 Mestre em Ciências Ambientais, Universidade do Extremo Sul Catarinense - UNESC, e-mail: marcelogryczak@ hotmail.com

5 Mestre em Administração, Universidade do Extremo Sul Catarinense - UNESC, e-mail: izabelrsouza@gmail.com
} 
metal mechanical industry of Southern Santa Catarina. Regarding the methodology, it is characterized as the ends as a descriptive research, and of ways to research, as a literature search and a case study. Data were collected through an on-site visit in the industry and also through an interview with engineers and industrial director, to understand all processes under study. With the support of trained professionals, the industry contemplates in its industrial activities sustainable practices in the rolling process, drawing and casting, involving treatment and water reuse, separation of oil and water, reuse of industrial towels, reuse scrap as raw material and recycling products with other specialized companies.

Keywords: Sustainability. Industry. Mechanical Metal.

\section{INTRODUÇÃO}

A crescente preocupação com a qualidade ambiental direcionou as indústrias para alternativas tecnológicas mais limpas e matérias primas menos tóxicas com a finalidade de reduzir o impacto e a degradação ambiental. Diante disso, as indústrias têm investido na modificação de processos, aperfeiçoamento de mão de obra, substituição de insumos, redução da geração de resíduos e racionalização no consumo de recursos naturais (DIAS, 2007).

O aço é a matéria prima fundamental da indústria metal mecânica, e está presente na construção civil, nas indústrias automobilísticas, utilidades domésticas e bens de consumo em geral. Pode-se identificar sua importância no desenvolvimento econômico nacional, pois é o fornecedor das principais indústrias de consumo do país (AÇOBRASIL, 2014).

Nota-se uma logística reversa praticada por este setor, pois os produtos metálicos acabados esgotam suas vidas úteis, são facilmente reinseridos como matéria prima na fabricação de um novo produto. Desta forma, minimiza-se a necessidade de extração de minérios diretamente do solo, visto que este material não perde sua qualidade mesmo com o passar do tempo (AÇOBRASIL, 2014).

Porém, esse setor também pode ser considerado um grande poluidor, pois seus processos produtivos geram grande quantidade de resíduos e gases poluentes, tornandose este o grande desafio das empresas: minimizar os danos que são lançados ao meio ambiente (ABIFA, 2008).

Assim, a exploração descontrolada do meio ambiente tem causado desequilíbrios climáticos no planeta, gerando uma crescente preocupação ambiental nas grandes indústrias. Deste modo, as empresas precisam se remodelar de acordo com as exigências 
do mercado, surgindo assim, a necessidade de propor metodologias para reduzir os materiais descartados oriundos da produção e como solução para esta adversidade, o reaproveitamento deste material na fabricação de um novo produto (SEBRAE, 2014).

O chamado complexo metal mecânico constitui um conjunto extremamente amplo e diversificado de atividades econômicas, cuja característica comum consiste no fato de que os bens e serviços por eles produzidos consubstanciam tecnologias em que os conhecimentos e técnicas relacionados à produção, processamento e utilização de metais, constituem um componente dominante (IPECE, 2005).

A produção em Santa Catarina deste setor encontra-se concentrada em algumas regiões, com relevância no Norte e Sul do Estado e o Vale do Itajaí. Contabilizando em 2010 por volta de 7.404 empresas, um total de $16,38 \%$ de todas as indústrias catarinenses, dos quais $98,1 \%$ são micros ou pequenas empresas, as quais geram aproximadamente 99.524 empregos (SEBRAE, 2014).

Situado ao Sul do Estado de Santa Catarina, o município de Nova Veneza apresenta um total de 26 empresas enquadradas neste setor, no qual 20 apresentam-se como micros ou pequenas empresas, e as seis demais se incluem como empresas de médio porte, resultando em 1.534 colaboradores empregados por esta indústria (SEBRAE, 2014).

A indústria em estudo está há 69 anos no mercado e ao longo do tempo, ajustou suas técnicas e insumos, de modo que sempre buscou se adaptar ás normas ambientais vigentes. Em 2005 a indústria foi certificada com ISO 9001/2008. Dentre as atividades, destacam-se a fundição, laminação e trefilação de perfis em aço quadrado, chato, redondo e perfis especiais, contando também com a fabricação de peças para o setor ferroviário e construção civil.

Desta forma, o presente estudo tem por objetivo identificar as práticas sustentáveis na fundição, laminação e trefilação de uma indústria metal mecânica do Sul de Santa Catarina.

O estudo foi estruturado em cinco seções. A primeira é a introdução. Na segunda seção destacam-se aspectos relacionados com a sustentabilidade e a indústria metal mecânica. Os procedimentos metodológicos que ampararam a pesquisa se caracterizam como a terceira seção. Em seguida, apresentam-se os resultados da pesquisa, as considerações finais e as referências. 


\section{SUSTENTABILIDADE}

Deve-se entender sustentabilidade pela conservação dos recursos naturais de todo o ecossistema. Contudo, para as vidas que são dependentes deste sistema, também se torna uma luta social, visto que é um apelo para as próximas gerações que habitarão neste planeta e necessitarão destes mesmos recursos que hoje nos é abundante, mas que são limitados e cada vez mais está perto de seu fim, devido ao desperdício e produção desordenada (BUAINAIN; SABBATO; GUANZIROLI, 2006).

Deste modo, busca-se o remanejamento e a conservação das fontes de recursos não renováveis, resultando numa necessidade de mudança tecnológica e institucional, de modo que mantenha as necessidades humanas supridas para as populações presentes e futuras. Um desenvolvimento sustentável deve resultar na conservação do solo, da água, dos animais e da vegetação. Porém, além da preservação ambiental, deve ser tecnicamente apropriado, economicamente viável e socialmente aceitável (EHLERS, 1994; KAMIYAMA, 2011).

Contudo, o uso acelerado dos recursos disponíveis no meio ambiente, em concordância com os dejetos oriundos das indústrias e lançados na natureza, resultou num montante muito acima da capacidade de absorção pelo meio ambiente, resultando em níveis cada vez maiores de poluição do solo, da água e do ar. De imediato, transferese de um nível local para dimensões globais, tais como o aquecimento global, a elevação do nível dos oceanos, derretimento das geleiras, mudanças climáticas, entre tantos outros efeitos colaterais degradantes ao planeta (PEREIRA; MAY, 2003).

Diante desta problemática, estabeleceu-se em 1972 um relatório chamado "Os Limites do Crescimento" elaborado por Meadows e Dennis e vários outros cientistas pertencentes ao "Clube de Roma", e por meio de projeções matemáticas, obtiveram o crescimento da população da Terra. Contudo, concluiu-se que se o planeta continuasse no mesmo ritmo de aceleração, em até 100 anos, os recursos naturais se tornariam escassos e os níveis de poluição altamente perigosos (SEIFFERT, 2007).

Ainda em 1972, aconteceu uma conferência na cidade de Estocolmo, na Suécia que auxiliou na conscientização por parte da sociedade acerca dos problemas ambientais e projeções em relação ao futuro do planeta. Esta conferência serviu como norteadora de todos os outros acordos ambientais multilaterais que se sucederam, onde se procurou estabelecer um conceito a respeito das relações entre o ambiente e o desenvolvimento, denominado desenvolvimento sustentável (BARBIERI, 2004). 
Entretanto, tais acordos multilaterais colaboraram na consolidação de uma educação ambiental e no comportamento dos seres humanos perante a natureza que o cerca. Auxiliou no lançamento de estratégias para a continuidade da educação ambiental, e que seja proposta de maneira participativa e permanente, incorporando todas as faixas etárias e níveis de ensino, com a finalidade de incentivar novas práticas de preservação e conservação do meio ambiente (PHILIPPI JUNIOR; PELICIONI, 2002).

Deve-se considerar a Conferência das Nações Unidas sobre Meio Ambiente e Desenvolvimento, que foi também chamada como Cúpula da Terra, Rio 92 ou Eco 92, realizada em 1992 no Rio de Janeiro, um dos acontecimentos mais marcantes, que contou com a participação de Chefes de Estado de 178 países. Identificou-se nesse encontro que se faz necessário um desenvolvimento equilibrado, onde surjam tecnologias que combatam os impactos ambientais causados ao longo do tempo pela exploração desordenada, que os recursos naturais sejam suficientes para suprir as próximas gerações e que a luta pela sustentabilidade deve estar ligada ao desenvolvimento social e econômico das nações (MOURA, 2008).

Conforme afirmam Harrington e Knight (2001) conferências e organizações internacionais com cunho para a discussão de parâmetros de saúde ambiental, foram criados com o intuito de alertar a população e encontrar soluções para esta problemática relacionada ao descaso com o meio ambiente, e apresentar o resultado em longo prazo. Deste modo, a eficiência dos projetos traçados teriam resultados factíveis.

\subsection{SUSTENTABILIDADE NA INDÚSTRIA METAL MECÂNICA}

Pode-se considerar que dentre as indústrias, as que possuem maior necessidade de práticas sustentáveis estão as que utilizam energia elétrica demasiadamente, ou as indústrias exploradoras de recursos naturais e seus derivados. Dentre elas, destacam-se as indústrias dos setores químicos, automotivo, metal mecânico, eletrônico e de papel e celulose (ALMEIDA; CAVALCANTI; MELLO, 2000).

As indústrias metal mecânicas sempre foram reconhecidas como de alto impacto ambiental pelas organizações de diversos setores. Porém, ao longo de seu processo evolutivo, este segmento industrial recebeu modificações após a inspeção severa dos órgãos ambientais, com a finalidade de minimizar os impactos ambientais, foram desenvolvidas tecnologias em seus processos produtivos (BRUM et al, 1996). 
A indústria metal mecânica vem buscando melhorias periódicas de seus processos e desenvolve várias pesquisas com enfoque na fabricação de aços especiais. Isso demonstra a crescente necessidade por tecnologias e o alcance de um produto de excelência derivados da siderurgia brasileira. Nota-se a condecoração internacional da integridade e da eficácia da siderurgia nacional, devido sua competitividade, estrutura de produção, sua tecnologia e seu baixo custo (ABM, 2013).

Diante dos desafios enfrentados pelas indústrias na busca de uma produção mais limpa, o setor metal mecânico é considerado um setor chave não só por suas indústrias, mas por tantas outras pertencentes a outros segmentos econômicos, haja vista que é uma indústria de transformação e existe dependência de tantos outros setores por seus produtos. Apresenta-se numa posição estratégica ao crescimento da economia nacional, deste modo, a busca contínua por novas técnicas de produção, surge a necessidade em identificar quais os dejetos oriundos dessa produção e difundir os métodos mais eficazes na redução destes resíduos, tamanha a importância deste setor no país (ADÃO; DIAS, 2012).

O setor da metalurgia pode ser considerado um grande gerador de resíduos sólidos resultados de seus processos produtivos, tais resíduos são denominados escórias, que possuem diversificadas estruturas químicas, e se diferem em relação á matéria prima ou os processos produtivos que forem adotados. Diante desta problemática ambiental, entende-se como primordial a necessidade da reformulação dos processos a fim de minimizar a produção de resíduos, visto que a estocagem inapropriada dessas escórias podem contaminar o solo e a água (CASSA; CARNEIRO, 1998).

Contudo, foram elaboradas algumas pesquisas para utilizar a escória de ferrocromo na substituição ao agregado graúdo na fabricação de concreto, as escórias de ferrocromo e de cobre, apresentam grande potencial para uso como material de construção. Porém, é necessário um estudo minucioso, visto que a utilização desses dejetos em outros produtos deve levar em conta o perigo de contaminação ambiental e da saúde dos usuários e trabalhadores (CASSA; CARNEIRO, 1998).

Para combater a problemática ambiental nas organizações, é necessário destacar alguns fatores, tais como: i) Identificar as tecnologias e os investimentos necessários para aquela atividade industrial; ii) A procedência da matéria prima utilizada, de modo que não agrida o meio ambiente; iii) A otimização dos recursos oriundos do processo produtivo; $i v)$ Métodos para a redução da poluição e da fabricação de resíduos; v) 
Disponibilidade de recursos da empresa para as melhorias necessárias; vi) Redução de riscos aos trabalhadores, devido a importância dos mesmos para o sucesso da organização, promovendo treinamentos contínuos (DONAIRE, 1999).

Com o intuito de elaborar uma previsão em relação ao cenário econômico da indústria metal mecânica de Santa Catarina, a Federação das Indústrias do Estado de Santa Catarina - FIESC (2014) elaborou com a ajuda de especialistas, algumas visões de futuro para que este setor torne-se referência até o ano de 2022. Uma delas aponta para o campo da sustentabilidade, deste modo essa indústria alcançaria o crescimento econômico desejado, promovendo a preservação do meio ambiente e o desenvolvimento social.

Conforme a visão dos especialistas pode ser um empecilho para o desenvolvimento sustentável no setor metal mecânico, o fato da elevada carga tributária, burocracia, demora na liberação das licenças ambientais obrigatórias, falta de conscientização ou estímulos para com os empresários na implantação de ações sustentáveis, a falta de estrutura do sistema logístico no estado, o alto custo com energia, e a falta de conscientização da população acerca do tema sustentabilidade (FIESC, 2014).

Para que se tornem realidade essas previsões é necessário a redução ou reutilização dos resíduos derivados da produção, por meio de novas técnicas eficientes que proporcionem maior aproveitamento dos recursos que estão a disposição da empresa, maior eficácia no uso da energia, buscar diminuir o consumo de forma a não prejudicar os resultados da mesma (FIESC, 2014).

\section{PROCEDIMENTOS METODOLÓGICOS}

Em relação aos fins de investigação, a pesquisa designa-se como descritiva, pois descreve a práticas sustentáveis nos processos de laminação, trefilação e fundição. É característica das pesquisas descritivas a narração acerca de um determinado tema, podendo ser aplicada em diversas modalidades, onde é caracterizada pelos métodos aplicados para a obtenção dos resultados desejados, sendo os mais comuns, a aplicação dequestionários ou até mesmo a observação sistemática (GIL, 1996).

Quanto aos meios de investigação a pesquisa caracteriza-se por uma pesquisa bibliográfica e um estudo de caso (SALVADOR, 1982, BARROS; LEHFELD, 2000). 
Os dados utilizados são de origem primária, pois foram coletados por meio de uma visita in loco na indústria e também entrevista com Engenheira Ambiental, Engenheiro de Materiais, Engenheiro Químico e o Diretor Industrial, objetivando compreender os processos industriais em estudo.

Por meio de entrevistas, o pesquisador obteve as informações que necessita, onde na maioria das vezes, as entrevistas envolvem poucas perguntas abertas de modo a extrair as opiniões dos entrevistados em relação ao tema, sem que nenhuma intervenção externa interfira nos resultados obtidos (CRESWELL, 2007).

A abordagem utilizada nesta pesquisa é definida como qualitativa (CARVALHO et al, 2001), uma vez que foi embasada na observação e transcrição dos processos de laminação, trefilação e fundição.

\section{APRESENTAÇÃO E DISCUSSÃO DOS RESULTADOS}

Destacam-se a seguir de forma sintetizada os processos, bem como as práticas sustentáveis, as atividades para melhoria dos processos e reaproveitamento de recursos.

\subsection{PROCESSOS DE LAMINAÇÃO, TREFILAÇÃO E FUNDIÇÃO}

O processo de laminação tem como finalidade reduzir as dimensões de blocos e barras por meio da conformação mecânica, tornando-os mais compridos e melhorando as características do material, como a sua superfície, resistência e maleabilidade. Para tal, é necessário transpassar o metal entre dois cilindros, cujos giram em sentidos contrários e velocidades iguais (SCHEAFFER, 1999).

Este processo inicia-se na elaboração da ordem de pedido, conforme as especificações do cliente, definindo assim, a matéria prima (placas ou tarugos). Após a escolha da matéria prima, são calculadas as dimensões do produto, logo em seguida, é efetuado o corte por meio de oxicorte. Cortado, o material é encaminhado para um forno de indução que pode chegar a até $1200{ }^{\circ} \mathrm{C}$.

Com a temperatura e o tempo ideal, este material é encaminhado para a máquina de laminação, passando por cilindros de um lado para outro diversas vezes até alcançar as dimensões e comprimentos desejados. Como a temperatura do material é elevada, ao passar pelos cilindros é necessário água para resfriá-los. Quando o material alcança as dimensões desejadas, é empilhado e aguarda seu esfriamento. 
Atingido a temperatura ambiente, o material é encaminhado para uma tesoura para receber o corte de suas pontas no comprimento ideal, deixando-as uniformes. Após este processo, o material é conduzido, passando por rolos que deixam a superfície lisa e homogênea, conforme ilustrado na Figura 1.

Figura 1 - Etapas de laminação.

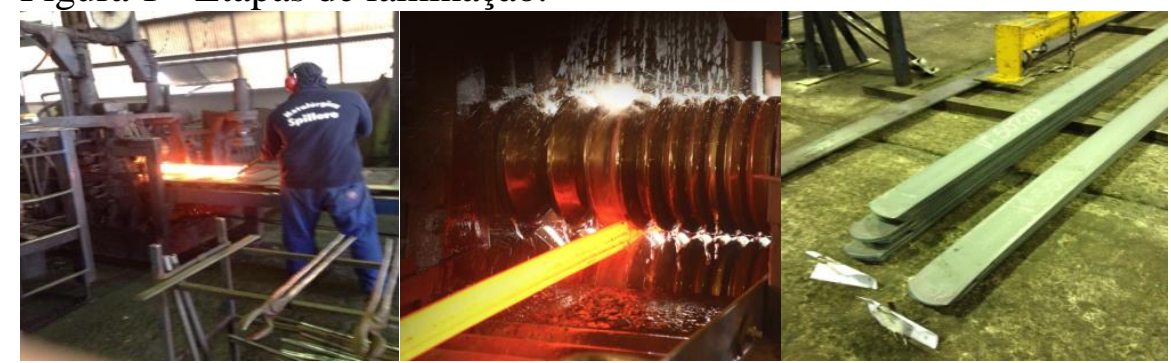

Fonte: Dos Autores (2015).

Com relação ao processo de trefilação, este se inicia após o material laminado, pois passando pela trefilação, o produto possui maior precisão em seus perfis, garantindo um melhor acabamento em relação ao produto apenas laminado, onde o material sofre alguns tratamentos químicos e físicos. Portanto, a matéria prima do processo de trefilação é o material laminado.

As barras de material laminado recebem argolas em sua extensão, com a finalidade de separar uma barra da outra, pois são amarradas em feixes e, posteriormente, o material é imerso em um tanque com ácido sulfúrico e ácido clorídrico, com a função de limpar as peças.

Quando a decapagem finalizada, o material é suspenso pela ponte rolante sobre o tanque para escorrer a solução ácida que possa estar carregando. Após a decapagem, lava-se o excesso de ácido com água até retirar toda a espuma do material, e em seguida, deve-se imergir o material em outro tanque com neutralizador durante trinta segundos, com o objetivo de evitar a oxidação das barras.

Em seguida, o material é colocado na máquina de trefilação, passando óleo e cal por toda sua extensão para diminuir o atrito da máquina com a peça. $\mathrm{O}$ material passa por uma fieira a frio que possui as dimensões do produto final, e com isso o material reduz a espessura, com aumento em seu comprimento.

Posteriormente, o material passa pelo mesmo processo de acabamento do material laminado, passando pela tesoura onde é feito o despontamento e o corte do material no comprimento ideal. Após este processo, o material é conduzido, passando 
entre rolos que deixam sua superfície lisa e homogênea. Depois disso, recebe óleo para que não sofra corrosão devido ao tratamento com ácido, conforme ilustrado em subsequência (Figura 2).

Figura 2 - Etapas de trefilação.

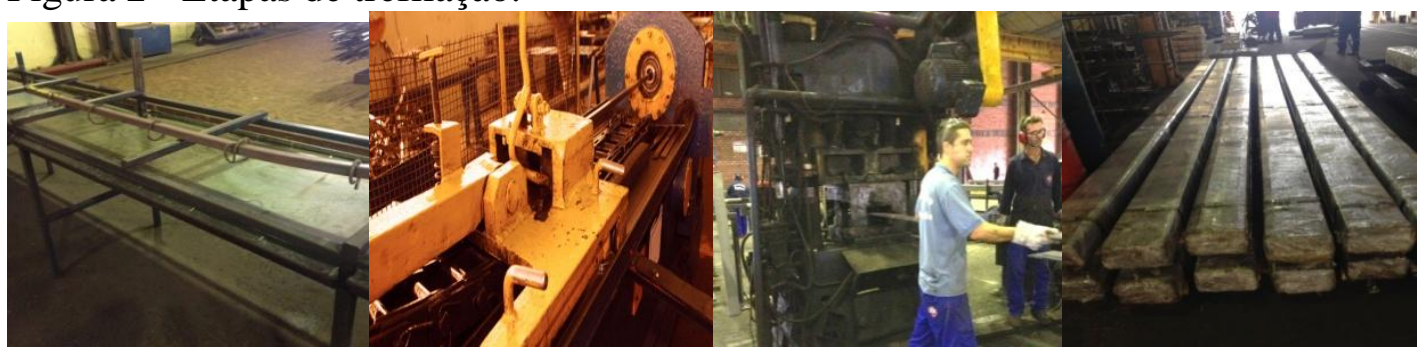

Fonte: Dos Autores (2015).

Já o processo de fundição inicia por meio de um modelo, que é uma caixa feita de madeira e possui a réplica do produto final. Com o modelo, cria-se o molde, feito a partir do preenchimento do modelo com areia resinada. Esta areia é prensada dentro do modelo e é acrescentada resina fenólica para garantir a resistência do molde, que logo após é retirado da caixa de madeira, estando apto a receber o metal líquido.

Com os moldes prontos, é feito o derretimento dos metais que compõem a liga metálica, dentro de fornos revestidos com tijolos refratários. Após atingir o ponto de fusão, o metal líquido é transferido para uma espécie de panela, também revestida pelos mesmos tijolos dos fornos, e desta panela o metal é vazado dentro dos referidos moldes.

Portanto, é aguardado o resfriamento e solidificação das peças em metal dentro dos moldes. Quando alcançada a temperatura ambiente, a peça é encaminhada para uma máquina, onde ocorre a quebra do molde em areia e separação da peça. Esta máquina conduz a areia utilizada para o processo de reaproveitamento, através de esteiras.

A peça passa pelo oxicorte para a retirada dos seus canais e das sobras obtidas, depois disso, o produto é encaminhado para rebarbação, onde é lixada e há uma atenção especial para os acabamentos, transformando-o muitas vezes na sua forma final, encaminhada para a expedição (Figura 3).

Figura 3 - Etapas fundição.

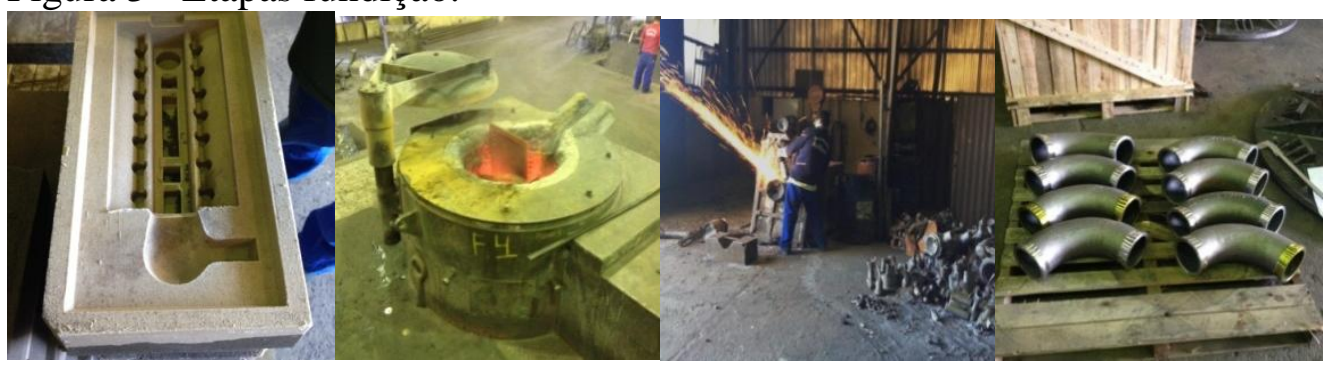


Fonte: Dos Autores (2015).

Caso seja necessário, e de acordo com as especificações do pedido, as peças podem ser usinadas, pintadas e envernizadas, porém, a usinagem não é efetuada na empresa, sendo assim terceirizada.

\subsection{PRÁTICAS SUSTENTÁVEIS NA LAMINAÇÃO}

Buscando se enquadrar nas normas ambientais vigentes, a indústria adota algumas medidas em relação aos resíduos gerados em seu processo produtivo. Em relação aos Equipamentos de Proteção Individual (EPI) contaminados com óleo, e outros produtos químicos, estes são armazenados em tambores de 200 litros fornecidos pela Colix e recolhidos por esta mesma empresa a cada 15 dias, gerando uma quantidade de $250 \mathrm{~kg}$ por mês, portanto este resíduo fica totalmente em responsabilidade da Colix.

Outro resíduo produzido são as toalhas industriais (estopas) que são armazenadas dentro dos sacos fornecidos pela empresa Atmosfera, são recolhidos a cada 15 dias, gerando um total de 1.500 unidades por mês, e posteriormente desinfetadas e reutilizadas. Os pedaços das barras de ferros que são cortadas na tesoura são reutilizados no processo de fundição como matéria prima.

Devido à laminação utilizar água em seu processo para o resfriamento dos cilindros, esta água acaba contaminada com óleo da máquina. Neste caso, a indústria possui uma caixa separadora de água e óleo, onde a água recebe tratamento e é reutilizada no processo de laminação e o óleo é armazenado e, posteriormente comercializado com empresas de refino, conforme ilustrado na Figura 4.

Figura 4 - Caixa separadora de água/óleo.

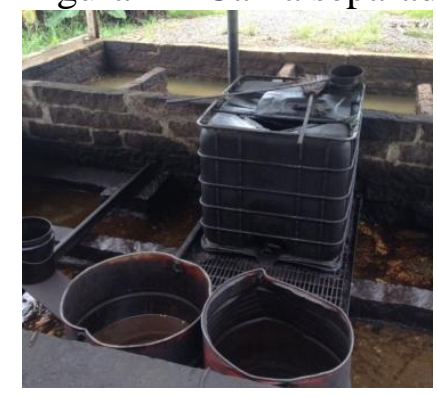

Fonte: Dos Autores (2015). 
Outro resíduo gerado no processo produtivo da laminação é a carepa, ilustrado na Figura 5, proveniente do forno utilizado para laminação. Este resíduo é vendido para empresas de reciclagem.

Figura 5 - Carepa da laminação.

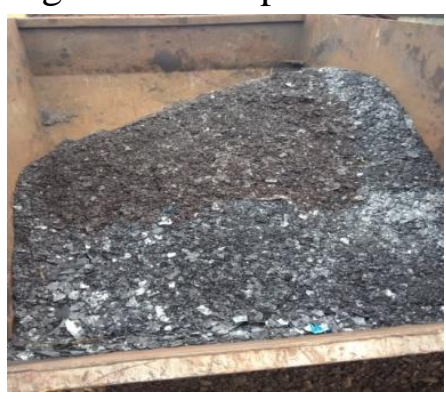

Fonte: Dos Autores (2015).

Deste modo, as práticas na laminação demonstradas refletem o compromisso no âmbito da responsabilidade sustentável nesta etapa do processo produtivo.

\subsection{PRÁTICAS SUSTENTÁVEIS NA TREFILAÇÃO}

Os EPIs contaminados com óleo e das toalhas industriais (estopas) possuem o mesmo destino, já mencionado no processo de laminação.

Todo óleo usado no processo produtivo da trefilação é armazenado em tambores de 200 litros e o local coberto e impermeabilizado, gerando um total de 800 litros por mês, são posteriormente vendidos para empresas de refino. O tanque de ácido utilizado no processo de trefilação é lavado a cada três meses, onde é feito o tratamento e a separação do ácido da água, como apresentado na Figura 6

Figura 6 - Estação de tratamento.

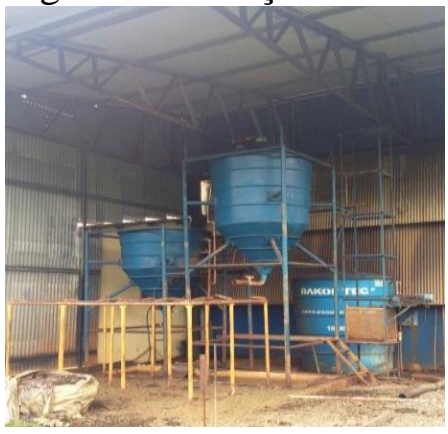

Fonte: Dos Autores (2015).

O ácido tratado resulta em um lodo, ilustrado na Figura 7 e a água é tratada em um sistema de estabilização de $\mathrm{pH}$. 
Figura 7 - Lodo ácido.

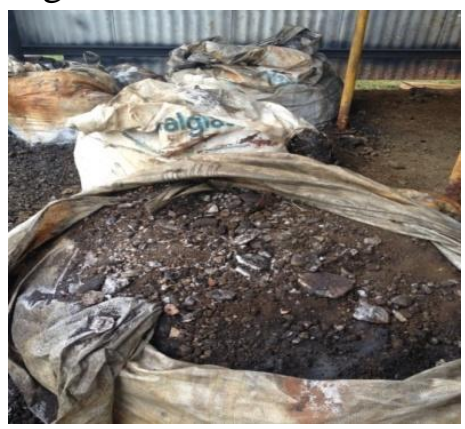

Fonte: Dos Autores (2015).

O lodo do ácido é armazenado em local impermeabilizado e depois recolhido pela empresa Colix, uma vez ao mês, totalizando $250 \mathrm{~kg} / \mathrm{mês}$.

\subsection{PRÁTICAS SUSTENTÁVEIS NA FUNDIÇÃO}

Neste processo, os EPIs contaminados com óleo e as toalhas industriais (estopas) também possuem o mesmo destino mencionado nos processos de laminação e trefilação.

Em relação a areia, pode-se afirmar que $70 \%$ podem ser reaproveitadas no processo produtivo. Do restante, é necessário ser complementado com areia nova para garantir uma maior durabilidade da peça. Depois de realizada uma avaliação física e química, verifica-se o $\mathrm{pH}$ e estando alterado, necessita de um ajuste na proporção de areia nova e reutilizada. Acertado o $\mathrm{pH}$, é acrescentado resina fenólica para garantir resistência do molde.

Esta resina deve ser dosada, pois quanto maior a quantidade de resina, maior a dificuldade em reaproveitar a areia. Toda a areia que não pode ser reaproveitada é encaminhada para aterro industrial pela Santech, representando-se este processo na Figura 8.

Figura 8- Silos de areia. 


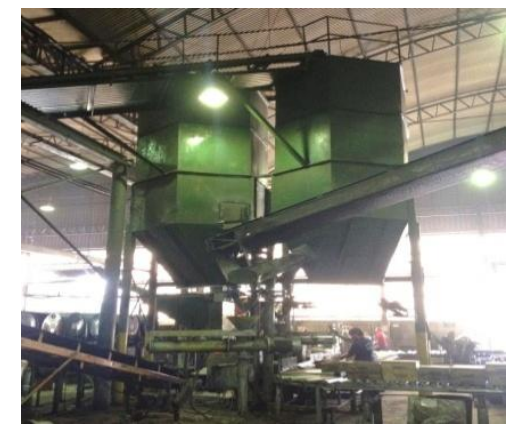

Fonte: Dos Autores (2015).

O processo de fundição pode ser considerado um grande reciclador, pois reutiliza os refugos de outros processos produtivos, até mesmo do seu próprio processo e sucatas variadas ilustrado na Figura 9.

Figura 9 - Sucatas e refugos.

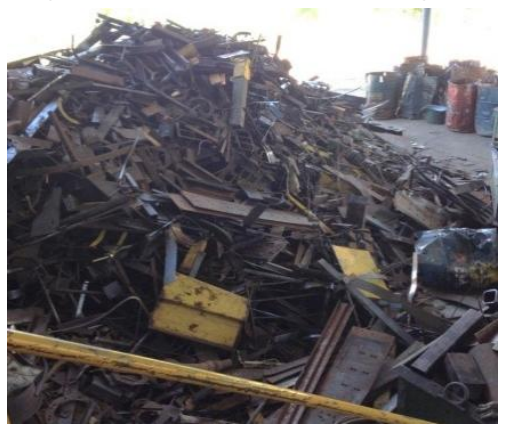

Fonte: Dos Autores (2015).

Dos metais utilizados no processo de fundição 42,5\% são derivados do próprio processo de fundição, tais como os canais que são retirados e peças com algum defeito de fabricação. 35,8\% correspondem ao retorno do refugo da laminação e sucata fundida. $14,2 \%$ são sucatas especiais, e apenas $7,4 \%$ correspondem a ferro liga e ferro gusa.

Outra prática sustentável realizado na fundição é a utilização de um filtro manga no pavilhão, responsável por capturar todo material particulado, que fica na atmosfera. Esse material é armazenado e encaminhado para aterro industrial pela Santech, de acordo com a Figura 10.

Figura 10 - Filtro manga. 


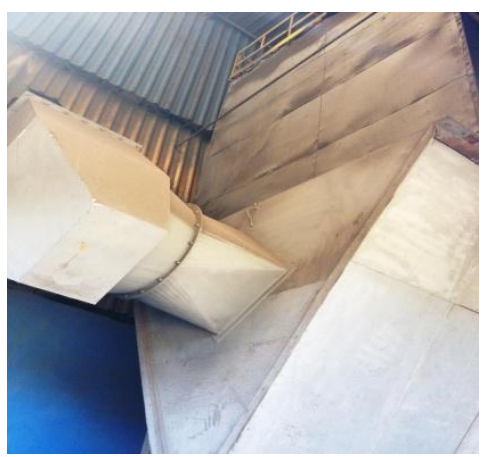

Fonte: Dos Autores (2015).

Também é de responsabilidade da Santech o transporte de todo resíduo não reutilizado derivado da etapa fundição, como também o tijolo refratário, somando um montante de 300 toneladas por mês de material transportado pela Santech derivados da fundição com destino a aterro industrial, com uma despesa de $\mathrm{R} \$ 70,00$ por tonelada e 200 reais por carga, todos estes materiais são armazenados pela empresa em locais impermeabilizados, com o intuito de não contaminar o solo.

\section{CONSIDERAÇÕES FINAIS}

Diante de uma reflexão contemporânea, se discute as limitações dos recursos não renováveis, e é comum a preocupação com o que a escassez destes recursos pode representar em esferas globais.

Contudo, as indústrias são cada vez mais fiscalizadas, diante do surgimento de normas e organismos ambientais que fiscalizam suas práticas. Deve-se levar em conta também a conscientização da população, os clientes se tornam mais exigentes, buscando não somente um produto, mas optando por empresas que respeitem o ambiente em que estão inseridas. Tal fato torna-se um passo positivo vinculado ao nome da empresa. A tendência é de que esse tipo de indústria cresça ao longo do tempo, e para tal, se faz importante que sejam divulgados os exemplos bem sucedidos, de modo a incentivar outras organizações da viabilidade e vantagens dessas mudanças.

Neste contexto, foi possível identificar as práticas sustentáveis na fundição, laminação e trefilação de uma indústria metal mecânica do Sul de Santa Catarina, por meio de uma pesquisa a campo, juntamente com o suporte do Engenheiro de Materiais, Engenheiro Químico, Engenheira Ambiental e o Diretor Industrial da indústria.

O Quadro 1 apresenta uma síntese dos principais resultados decorrentes das práticas sustentáveis nas etapas de laminação, trefilação e fundição, objetos deste estudo. 
Quadro 1 - Síntese dos resultados.

\begin{tabular}{|c|c|}
\hline SETOR & PRÁTICAS SUSTENTÁVEIS \\
\hline Laminação & $\begin{array}{l}\text { - Caixa separadora de água e óleo e o reaproveitamento da água; } \\
\text { - Comercialização do óleo para empresas de refino; } \\
\text { - Venda da carepa para empresas de reciclagem. }\end{array}$ \\
\hline Trefilação & $\begin{array}{l}\text { - } \quad \text { Armazenamento e posterior comercialização do óleo; } \\
\text { - } \quad \text { Estação de separação de água e ácido; } \\
\text { - } \quad \text { Tratamento do ph da água e reaproveitamento. } \\
\end{array}$ \\
\hline Fundição & $\begin{array}{l}\text { - Reaproveitamento de até } 70 \% \text { da areia de fundição; } \\
\text { - } \quad \text { Reutilização de diversas sucatas como matéria prima; } \\
\text { - } \text { particunação de um filtro manga responsável por capturar todo material } \\
\end{array}$ \\
\hline Todos os Setores & $\begin{array}{l}\text { - Toalhas industriais são desinfetadas e reutilizadas; } \\
\text { - Restos derivados dos processos produtivos ou peças com falhas são } \\
\text { reutilizados na fundição. } \\
\text { - Todo material que não pode ser reutilizado é armazenado em local } \\
\text { impermeabilizado e recolhido por empresas responsáveis pelo seu } \\
\text { encaminhamento. }\end{array}$ \\
\hline
\end{tabular}

Fonte: Dos Autores (2015).

Em relação aos resultados obtidos, pôde-se identificar que a empresa vem desempenhando esforços na busca por uma produção mais limpa e utilização dos resíduos passiveis de serem reaproveitados, agregando assim valor econômico ao produto desenvolvido.

Para que o tema continue em discussão sugere-se que novos estudos sejam realizados envolvendo a sustentabilidade nos processos das indústrias cerâmica e química do Sul de Santa Catarina, uma vez que a região é destaque na comercialização dos produtos oriundos destes processos industriais.

\section{REFERENCIAS}

ABIFA. Associação Brasileira de Fundição. Resíduos de fundição: solução a caminho. Revista Fundição \& Matérias-primas. 95ª ed. São Paulo, março, 2008.

AÇOBRASIL. Instituto Aço Brasil. Relatório de Sustentabilidade 2014: Instituto Aço Brasil, Publicação produzida pelo Instituto Aço Brasil que apresenta o desempenho econômico, ambiental e social da indústria do aço. Rio de Janeiro: Equipe Técnica do Instituto Aço Brasil, 2014. 93 p. Disponível em: <http://www.acobrasil.org.br/site2015/downloads/Relatorio_Sustentabilidade_2014.pdf >. Acesso em: 04 jun. 2015.

ADÃO, N. M. L.; DIAS, K. P. Economia verde e os desafios do setor metal mecânico. E-Tech: Tecnologia para Competitividade Industrial. n. esp. Metalmecânica, p. 1-13. SENAI: $\quad$ Florianópolis, $2012 . \quad$ Disponível em: 
$<$ http://revista.ctai.senai.br/index.php/edicao01/article/view/236/14>. Acesso em: 27 out. 2014.

ALMEIDA, J. R; CAVAlCANTI, Y.; MELlO, C. Gestão Ambiental: planejamento, avaliação, implantação, operação e verificação. Rio de Janeiro: Thex Ed., 2000.

BARBIERI, J. C. Gestão ambiental empresarial: conceitos, modelos e instrumentos. São Paulo: Saraiva, 2004.

BARROS, A. da S.; LEHFELD, N. A. de S. Fundamentos de metodologia: um guia para iniciação científica. 2.ed. São Paulo: Makron Books, 2000.

BRUM, I. A. S. et al. Mineração e meio ambiente: uma avaliação do Estado da Bahia Brasil. TECBAHIA, Revista Baiana de Tecnologia, v. 11, n. 3, p. 216-223, set./dez. 1996.

BUAinAin, A. M.; SABBATO, A. D.; GUANZIROLI, C. E. Agricultura Familiar: Um estudo de Focalização Regional. Sober - Sociedade Brasileira de Economia, Administração e Sociologia Rural, 2006. Disponível em: <http://www.sober.org.br/palestra/12/090437.pdf>. Acesso em: 4 out. 2014.

CARVALHO, A. M. et al. Aprendendo metodologia científica: uma orientação para os alunos de graduação. 2 ed. São Paulo: O Nome da Rosa, 2001.

CASSA, J. C. S.; CARNEIRO, A. P. Aplicação de uma escória de ferrocromo como agregado graúdo de concreto de alto desempenho. In: CONGRESSO ANUAL DA ABM. Belo Horizonte, 1998.

CRESWELL, J. W. Projeto de pesquisa: métodos qualitativo, quantitativo e misto. 2. ed Porto Alegre: Artmed, 2007.

DIAS, R. Gestão ambiental: responsabilidade social e sustentabilidade. São Paulo: Atlas, 2007.

DONAIRE, D. Gestão ambiental na empresa. 2.ed. São Paulo: Atlas, 1999.

EHLERS, E. M. O que se entende por agricultura sustentável? São Paulo: USP, 161f. Dissertação (Mestrado em Ciência Ambiental) - Programa de Pós-Graduação em Ciência Ambiental, São Paulo: Universidade de São Paulo, 1994. Disponível em: <http://www.teses.usp.br/teses/disponiveis/90/90131/tde-25112011-091132/pt-br.php >. Acesso em: 7 out. 2014.

FIESC. Federação das Indústrias do Estado de Santa Catarina. Rotas Estratégicas Setoriais para a Indústria Catarinense 2022: Metal mecânico \& metalurgia. Florianópolis: 2014. Disponível em: <http://www4.fiescnet.com.br/images/homepedic/Metal-mecanico\%20-\%20Caderno.pdf >. Acesso em: 10 out. 2014.

GIL, A. C. Como elaborar projetos de pesquisa. 3 ed. São Paulo: Ed. Atlas, 1996. 
HARRINGTON, H. J.; KNIGHT, A. A implementação da ISO 14000: como atualizar o SGA com eficácia. São Paulo: Atlas, 2001.

IPECE. Instituto de Pesquisa e Estratégia Econômica do Ceará. Estudos Setoriais. Aprendizado competitivo e oportunidades da indústria metal mecânica no nordeste. 2005. Fortaleza.

KAMIYAMA, A. Cadernos de Educação Ambiental: agricultura sustentável. São Paulo: Secretaria do Meio Ambiente, 2011. Disponível em: <http://www.ambiente.sp.gov.br/wp-content/uploads/publicacoes/sma/13-

AgriculturaSustentavel.pdf $>$. Acesso em: 9 out. 2014.

MOURA, L. A. A. de. Qualidade e gestão ambiental: sustentabilidade e implantação da ISO 14.001. 5.ed. São Paulo: Juarez de Oliveira, 2008.

PEREIRA, A. P.; MAY, P. H. Economia do aquecimento global. In: MAY, Peter H., LUTOSA, Maria Cecília, VINHA, Valéria. Economia do meio ambiente: teoria e prática. Rio de Janeiro: Campus, 2003.

PHILIPPI JUNIOR, A.; PELICIONI, M. C. F. Educação ambiental: desenvolvimento de cursos e projetos. 2. Ed. São Paulo: Signus, 2002.

SALVADOR, A. D. Métodos e técnicas de pesquisa bibliográficas. 10 ed. Porto Alegre: Ed. Sulina, 1982.

SCHAEFFER, Lírio. Conformação mecânica. Porto Alegre: IL, 1999.

SEBRAE. Serviço de apoio as micro e pequenas empresas de Santa Catarina. 2014. Disponível em: $\langle$ http://www.sebrae-sc.com.br/leis/default.asp?vcdtexto=4154>. Acesso em: 3 nov. 2014.

SEIFFERT, M. E. B.; Gestão ambiental: instrumentos, esferas de ação e educação ambiental. São Paulo: Atlas, 2007. 